IP Periodica Polytechnica

Social and Management

Sciences

25(1), pp. 1-7, 2017

DOI: $10.3311 /$ PPso.8919

Creative Commons Attribution (i)

RESEARCH ARTICLE

\section{The Paradox of Sustainable Development: A Critical Overview of the Term and the Institutionalization Process}

\author{
Gauri Shankar Gupta ${ }^{1 *}$
}

Received 17 December 2015; accepted after revision 09 March 2016

\begin{abstract}
Although the concept of sustainable development is not new it has acquired new impetus since early 80s, becoming one of the most debated and written subjects in the recent years. Intellectuals as well as ordinary mortals all across the globe are engaged in this debate. United Nations, international agencies, NGOs, national institutions, governments and civil societies are actively participating in this intense debate. Purpose of this paper is to bring out the concept and paradox of sustainable development, to provide a brief overview of global negotiations on this subject, to have a look at the prevailing ground realities despite plethora of negotiations and declarations and to highlight simple truths of human behaviour based on ancient wisdom. Most of these simple truths have remained obscured under the shadow of plethora of documents and declarations written in highly technical and unintelligible jargons.
\end{abstract}

\section{Keywords}

sustainability, economic groth, social awareness

\footnotetext{
${ }^{1}$ High Commissioner of India, Port of Spain, Trinidad and Tobago

*Corresponding author, e-mail: gaurishankargupta@yahoo.co.in
}

\section{Defining Sustainable Development}

Sustainable development has been defined in a variety of ways, but the most frequently quoted and accepted definition so far is from Our Common Future, also known as the Brundtland Report (Brundtland, 1987:p.41).

"Sustainable development is development that meets the needs of the present without compromising the ability of future generations to meet their own needs. It contains within it two key concepts:

- the concept of needs, in particular the essential needs of the world's poor, to which overriding priority should be given; and

- the idea of limitations imposed by the state of technology and social organization on the environment's ability to meet present and future needs."

Thus, how the needs of the present generation are balanced without jeopardizing the needs of the posterity - in environmental, economic and social contexts - constitutes the core of sustainable development. Goals of economic prosperity, social equity and environmental protection are certainly desirable and non-controversial. The core question is whether they are attainable and compatible. Many learned scholars argue that we need to continue with economic growth and higher consumption as our population rises in order to help those who are suffering from deprivation, poverty and malnutrition. Many others hold the view that this ever growing consumption could substantially deplete our natural resources, contaminate the environment and probably cause irreparable damage to our ecosystem; thus endangering the very existence of future generations. Therefore the question arises whether sustainable development is an attainable goal or simply an oxymoron. In addition, developing countries with widespread poverty and malnutrition also argue that the campaign for environmental protection and sustainability is nothing but a new form of colonization by the developed North to keep the developing countries in perpetual state of poverty and deprivation.

Concepts and paradox of sustainable development has been examined in considerable detail by Susan Baker et al. (1997) 
and by Rob J. Krueger and David Gibbs (2007). A very appealing and conceptually clear summary of this paradox was provided in 1999 by Willard R. Fey and Ann C.W. Lam, who refer to it as the Ecocosm Paradox (Fey and Lam, 2001:p.11). The Ecocosm Paradox is the set of dilemmas that arise from the compound hyper-exponential growth of annual world human consumption. The two main characteristics of the Ecocosm Paradox are:

- If human consumption growth continues, the planetary life support system will be disabled and the very existence of humanity will be endangered.

- If the consumption growth is stopped the viability of the global economic and financial system will be threatened endangering the stability of governments, social systems and individuals.

At the first look these contradictions look irreconcilable and insurmountable. However if we look at human life closely; paradoxes, opposites and vicious circles are a regular and inevitable reality. They exist in every domain of human life; like day and night. Poverty and prosperity, sadness and happiness, rational and emotional, love and hatred, war and peace - are a few such examples. We need to reconcile and overcome these contradictions with judicious approach and move forward in our civilizational march. The Brundtland Report also acknowledges that environmental protection and development are not incompatible. Right to healthy and productive life and self development is an inherent human right and cannot be denied so is the right to existence and self development of our posterity. Since nature is the only source of our survival, both these rights can exist and survive only in harmony with nature. Therefore clear understanding of human needs, relationship between man and nature, moderation in human conduct with judicious use of resources are the way out. A vision based on more humane and less materialistic society is the need of the hour. I will deal with this issue in detail in the last section of this paper. Let us first have a brief look at the historical perspective and global negotiations on sustainable development. These will provide us better understanding and clarity of thoughts on this important issue.

\section{Brief History}

The concept of sustainable development is as old as human existence. It has engaged human mind since times immemorial giving birth to the idea of 'peaceful co-existence' with nature. After all; nature is the only source of all we consume in any form throughout our life from birth till death. Nature nurtures us. Human race is alive precisely because of the bounties of nature. Keeping this significant fact in mind our wise ancestors had integrated the concept of co-existence in the form of cultural practices to make it an integral part of our day-to-day life. For example in India respect for other species of life and vegetation is deeply rooted in the concept of 'non-violence'.
Cultural practices of worshipping animals, plants and birds are still prevalent in all parts of India. I vividly remember feeding animals and birds and watering plants in public spaces in my childhood. Plants of 'tulsi' and 'amla' are still worshipped in a large number of Indian homes. Vegetarianism and worshipping of animals including cows are based on the concept of protecting other species of life. During my stay in Mongolia (2003-2006) I found nomadic people extremely caring for nature - animals, water bodies and vegetation. In the course of my conversation with them they used to explain as to how their very survival is completely dependent of water bodies, plants and animals. They were highly critical of large scale mining and over-use of water bodies. Similarly I found the people in Hungary, particularly in rural areas, very caring for nature. I am sure these practices exist in other societies as well.

Large scale industrialization, mechanization of agriculture, new modes of transport, globalization, massive increase in use of natural resources, decline of rural industries and steady migration to cities has added a new dimension to this issue during the last few decades. The recent history of sustainable development goes back to early 1970s. At global level conflict between environment and development was first acknowledged in the 1972 Stockholm Conference on Human Environment which led to the establishment of United Nations Environment Programme (UNEP). In 1980 the International Union for Conservation of Nature and Natural Resources (IUCN) came out with the World Conservation Strategy highlighting the interdependence between the ecosystem and human existence (IUCN, 1980:p.14). The Strategy particularly highlights the urgent need for maintenance of essential ecological processes and life support systems, preservation of genetic diversity and sustainable utilization of species and ecosystems. Subsequently the World Commission on Environment and Development was commissioned by the United Nations General Assembly in 1982. The Commission headed by Gro Harlem Brundtland, Prime Minister of Norway presented its report titled "Our Common Future" in 1987.

As a follow up of this report the United Nations Conference on Environment and Development (also known as the Earth Summit) was held in Rio de Janeiro in 1992. The Summit adopted the famous 'Agenda 21' outlining coordinated international action to eliminate hunger, poverty and illiteracy and better protection of ecosystem and biodiversity (UNSD, 1992). This is a comprehensive document spread over 351 pages with 40 chapters. In addition three conventions were adopted at this Summit known as 'Rio Conventions'. These are United Nations Framework Convention on Climate Change (UNFCCC), UN Convention on Bio-diversity and the Convention to Combat Desertification. The Third Conference of Parties (COP) under UNFCCC led to adoption of Kyoto Protocol in December 1997 which came into force on $16^{\text {th }}$ February 2005 and expired in 2012. The Protocol provided mandatory targets for emission of greenhouse gases for the major economies in the world. 
These mandatory targets were based on projected $5 \%$ cut in the emission of greenhouse gases over the emission levels of 1990 (UNFCCC, 2014).

Ten years later in 2002 Johannesburg, South Africa at the World Summit on Sustainable Development, commitment to sustainable development was reaffirmed (UN, 2002). Separately to mark the beginning of new millennium a Summit meeting of Heads of Governments was held at UN Headquarters in New York in September 2000 where UNGA adopted about 60 new goals including 8 Millennium Development Goals (MDGs) towards reduction of poverty, illiteracy and malnutrition. These 8 MDGs became the global agenda for 15 years to tackle the indignity of poverty and hunger.

20 years after the Earth Summit in Rio, United Nations Conference on Sustainable Development (Rio+20) was held in Rio de Janeiro. The discussion during the conference focussed on two main themes; (1) how to build green economy to achieve sustainable development and lift people out of poverty and (2) how to improve international coordination on sustainable development. More than US\$513 billion were pledged to build a sustainable future. Rio+20 identified and highlighted the following major issues (UNCSD, 2012).

- The world today has 7 billion people - by 2050, there will be 9 billion.

- One out of every five people - 1.4 billion - currently lives on $\$ 1.25$ a day or less.

- A billion and half people in the world don't have access to electricity.

- Two and a half billion people don't have a toilet.

- Almost a billion people go hungry every day.

- Greenhouse gas emissions continue to rise and more than a third of all known species could go extinct if climate change continues unchecked.

23 years have elapsed since the Earth Summit at Rio. Since then hundreds of international conferences have taken place including Conference of Parties under UNFCCC. A plethora of documents, protocols and declarations have emerged out of these meetings. Thus the fundamental principles for building a just, sustainable, peaceful and harmonious global society are well documented. A large number of new institutions have emerged both at national and international levels to deal with the issue of sustainable development. Existing institutions have created new divisions to handle this issue. Thus there is no dearth of documentation and institutional framework.

Conference of Parties to UNFCCC (UNFCCC, 2015) has recently concluded its 21 annual session at Paris. Paris Agreement on reduction of greenhouses gases has been described as historic. In my view jubilation on the accord was more out of a sense of relief than accomplishment on its own merit. The document consists of two parts; (1) a decision of the Conference of Parties to the UNFCCC which is non-binding and (2) a Paris Agreement institutionalizing 'pledge and review system' whereby countries will be offering voluntary climate change action which will be periodically reviewed. The 34 page agreed document will be implemented from 2020. What legal form it will take and how it will be put to implementation is not yet clear. Nevertheless it is clear that the predominant focus of the document is on reduction in the emissions of greenhouse gases so that the rise in atmospheric temperature could be contained within $2{ }^{\circ} \mathrm{C}$ from the preindustrial level. The agreement also obliges the developed countries to contribute US\$100 billion every year for providing clean technologies to the developing countries and provides for a review of greenhouse gas emissions every five years with the first review starting in 2023. Global peaking of greenhouse gases at the soonest possible has been envisaged. A complicated regime monitoring carbon emissions will be put in place. Unfortunately the primary focus of the agreement is confined only to $\mathrm{CO}^{2}$ emissions. I have serious doubt about the success of this agreement unless the important issues mentioned in the last section of this article are also addressed simultaneously by the world community.

\section{Sustainable Development Goals}

In yet another significant development, 2030 agenda for sustainable development goals (SDGs) was adopted at the UN Sustainable Development Summit held at New York on 25-27 September, 2015. This became possible following noticeable success on 8 Millennium Development Goals adopted at the UN Millennium Summit in 2000. Findings of the Millennium Development Goals Report 2015 (MGD, 2015:p.6) show that the MGDs produced the most powerful anti-poverty movement lifting a billion people out of extreme poverty with considerable improvement in health, education and gender equality. Number of people living in extreme poverty declined from 1.9 billion in 1990 to 836 million in 2015. Primary school enrolment increased from 60 to $80 \%$. Considerable success was achieved against malaria, tuberculosis, HIV/AIDS. Child mortality rate registered a decline. However environmental degradation worsened with $50 \%$ increase in emission of Green House Gases, growing desertification, contamination of oceans and deforestation.

The 17 SDGs with 169 targets seek to eliminate extreme poverty and hunger, improve health and education, achieve gender equality, ensure supply of clean water and energy, achieve sustainable consumption and production patterns, reduce inequality among nations, promote innovation, make cities more sustainable and combat climate change and protect oceans, forests and ecosystem (UNGA, 2015). These 17 SDGs constitute a comprehensive and ambitious agenda for the next 15 years covering all the three pillars of sustainable development - economic wellbeing, social inclusion and environmental sustainability. These targets are not impossible to achieve but they do need a coordinated approach by governments, national and private sector institutions and civil societies. In this era of growing consumption environmental sustainability remains the biggest challenge. 


\section{Ground Realities}

While these complex negotiations have been going on in the comforts of five star hotels around the world at most exotic places, there is absolutely no mitigation in the factors affecting ecosystem and climate change. On the contrary the situation is deteriorating day by day as clearly indicated in the Rio +20 Report. Temperatures are rising, glaciers are melting, rivers and lakes are disappearing, bio-diversity is on a declining curve, species are becoming extinct, forest cover is declining, ocean beds and fertility of soil are being poisoned, weather conditions are becoming erratic and natural disasters are on the increase. NASA Website on Global Climate Change (NASA, 2016) provides the following ground realities:

1. The current global warming trend is of particular significance because most of it is very likely human-induced and proceeding at a rate that is unprecedented in the past 1300 years.

2. Global sea level rose about 17 centimetres in the last century. The rate in the last decade, however, is nearly double that of the last century.

3. All three major global surface temperature reconstructions show that Earth has warmed since 1880. Most of this warming has occurred since the 1970s, with the 20 warmest years having occurred since 1981 and with all 10 of the warmest years occurring in the past 12 years.

4. The oceans have absorbed much of this increased heat, with the top 700 meters of ocean showing warming of 0.302 degrees Fahrenheit since 1969.

5. The Greenland and Antarctic ice sheets have decreased in mass. Data from NASA's Gravity Recovery and Climate Experiment show Greenland lost 150 to 250 cubic kilometres of ice per year between 2002 and 2006, while Antarctica lost about 152 cubic kilometres of ice between 2002 and 2005.

6. Glaciers are retreating almost everywhere around the world — including in the Alps, Himalayas, Andes, Rockies, Alaska and Africa.

7. The number of record high temperature events in the United States has been increasing, while the number of record low temperature events has been decreasing, since 1950. The U.S. has also witnessed increasing numbers of intense rainfall events.

8. Since the beginning of the Industrial Revolution, the acidity of surface ocean waters has increased by about 30 percent. This increase is the result of humans emitting more carbon dioxide into the atmosphere and hence more being absorbed into the oceans. The amount of carbon dioxide absorbed by the upper layer of the oceans is increasing by about 2 billion tons per year.

National Geographic (2016) also confirms rising temperatures and global warming stating that the rate of warming is increasing and that the 20th century's last two decades were the hottest in 400 years and possibly the warmest for several millennia, according to a number of climate studies. The Arctic is feeling the effects the most. Average temperatures in Alaska, western Canada, and eastern Russia have risen at twice the global average, according to the multinational Arctic Climate Impact Assessment report compiled between 2000 and 2004. Glaciers and mountain snows are rapidly melting-for example, Montana's National Glacier Park now has only 27 glaciers, versus 150 in 1910. In the Northern Hemisphere, thaws also come a week earlier in spring and freezes begin a week later. An upsurge in the amount of extreme weather events, such as wildfires, heat waves, and strong tropical storms is also attributed in part to climate change by some experts.

Unfortunately, the international community is looking at the issue of sustainable development through a very narrow prism. Carbon/Greenhouse gas emissions constitute core of most of these international negotiations including those under UNFCCC. Many other important issues directly impacting on sustainable development have been completely ignored or conveniently left aside. Sustainable development is not dependent on carbon/greenhouse gas emissions alone. Sustainable development requires adequate respect for nature in a variety of ways. In the next section of this article I will try to list out some of these important issues which have been completely ignored by the global leaders. All these issues will have to be looked at in their totality if we want to achieve the goal of sustainable development for the present and the future generations.

\section{Need of the Hour}

From the brief history narrated above it is apparent that during the last three decades the governments, the NGOs and the so called experts have successfully converted a simple subject into a most complex matrix with hundreds of variables presented in thousands of tables and graphs running into millions of pages making it impossible for an ordinary folk to understand anything out of it. Intense debate have been going-on, on balance between environment and development, rights of the developing nations to improve quality of life of their citizens, the nature and number of environmental indicators, environmental sustainability index, carbon emissions, technology transfer, financing of new technologies and fixation of voluntary or legally binding targets on carbon emissions. Implementation of Paris Agreement will make it further complicated with new jargons. While for intellectuals and experts, such a debate is fascinating and intellectually satisfying, millions of poor people across the globe are suffering due to ravages of nature which are becoming more and more extreme every passing day. Moreover the economic path we are following today has imposed many life-style and societal changes which are highly detrimental to human well-being and are totally unsustainable. In my opinion durable solution to this problem is simple and 
straight forward. Let me summarise the proposed approach in the succeeding paragraphs.

a) Nature is our mother. The air we breathe, the water we drink, the food we eat, the habitation we live in, the clothes we wear and whatever else we consume comes from the Mother Nature. It will therefore be stupid to poison the very source of our survival. If we and our progeny need to survive we must respect and care for Mother Nature. This is ancient wisdom and a plain truth. No complex statistics, graphs or tables are needed to understand this simple fact.

b) Human race for higher and higher Gross Domestic Product (GDP) and per capita income are the root causes of this problem. Today every individual, every organization and every nation is looking for more and more resources and income. We have created a consumption driven society where everybody is perpetually hungry for more. Obviously in this race for more, more and yet more we are digging deep into the earth's surface, the ocean beds and even the ice covered Arctic and Antarctic. Forests are fast depleting, lakes are rivers are drying up due to over and imprudent consumption of these natural resources. Equipment and machinery invented since the industrial revolution has helped exploit nature far more than ever done in the past. As a result nature has been exploited in an unprecedented manner in the last 100 years. The amount of natural resources extracted for the production of goods and services is steadily increasing at around 60 billion tonnes each year, humans extract and use about $50 \%$ more than only 30 years ago. Global annual extraction of natural resources equals the weight of more than 41,000 Empire State Buildings, each weighing around 365,000 tonnes (Friends of Earth, 2009:p.3). Over the past 50 years humans have changed the ecosystem faster and more extensively than any period in human history (Green Facts, 2013). These new equipment of modern era have wounded each and every part of the body of Mother Earth leaving deep scars all over. Simultaneously we are poisoning the air, rivers, lakes, oceans and soil with unprecedented waste in a variety of forms. Desires are ever elastic and keep growing in geometric progression. In Sanskrit they are called trishna which can never be satisfied. One satisfied desire gives rise to many more. Therefore this greed for higher GDP and more and more consumption must come to a halt. Consumption driven approach to life is the single most important aggression against Mother Nature. Moderation and contentment are ancient dictum. Human needs can be fulfilled but not greed. If we fail to address this simple truth all international negotiations and agreements will lead us nowhere. They are doomed to fail.

c) Modern machinery for mass production has led to concentration of wealth and means of production in a few hands in an unprecedented way virtually destroying most of the small and village industries based on local resources. Today small and rural industries cannot survive against the might of MNCs with large scale production, massive financial resources and global market access. These large faceless units are also the source of massive pollution and misuse of natural resources. Death of small and rural industries and mechanization of agriculture has led to vast urbanization taking the human race away from nature to the vast concrete jungles leading to unprecedented levels of pollutions in urban areas, mountains of waste and a complete disconnect between man and nature. This societal and life-style change has also given birth to a large number of non-biodegradable materials. Moreover mass production with gigantic machines of modern times has reduced human beings to robots in flesh and blood. This is leading to large scale degeneration of human race. This could be seen in an assembly line unit where a man is performing a small repetitive action 8 hours a day - 365 days a year; virtually impairing his thinking and creativity. This is nothing but dehumanisation of human race. Human race has become a virtual slave of machinery. It is therefore important to revive small and rural industries by imposing prohibitive environmental tax on large production units to restore respect for nature. Small industries based on local raw materials are most suitable for sustainable development (Gupta, 2014:p.183) and must be encouraged.

d) Following the industrial revolution the scale of production has gradually risen due to mechanization. This gave rise to concentration of wealth and means of production and rise of MNCs. Thus, inequality of income and wealth has gone up in an unprecedented manner during the last 150 years and more so since the Second World War. Credit Swiss' Global Wealth Report estimates that in 2014 the richest $0.7 \%$ of world population owned $44 \%$ of global net worth (Institute of Policy Studies,n.d.). According the Institute of Policy Studies, Washington the world hosted 1645 billionaires in 2014 compared to 793 in 2009. According to the same source the combined wealth of 1645 billionaires alone was estimated at US\$ 6.4 trillion in 2014. In 2005 consumption by the poorest $20 \%$ of world population was only $1.5 \%$ while the richest $20 \%$ consumed $76.6 \%$ with approximately 1 billion people living in urban slums in sub-human conditions (Shah, 2013). According to the same source, distance between the rich and poor countries was approximately $3: 1$ in 1820 which went up to $72: 1$ in 1992 .

e) The Growth Report- Strategies for Sustained Growth and Inclusive Development by the Commission on Growth and Development set up by the World Bank has stated the following (World Bank, 2014). 


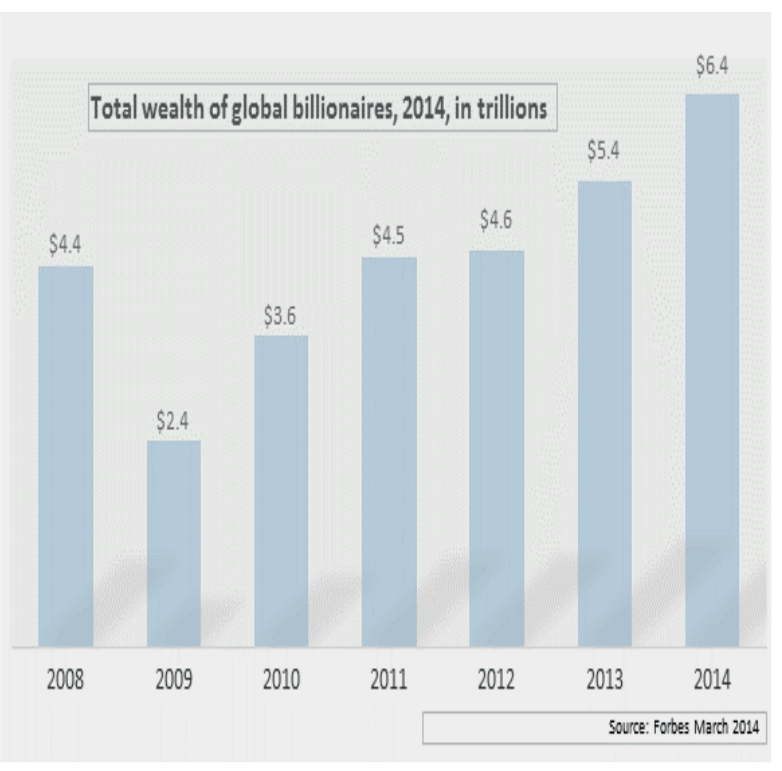

Fig. 1 Growth of Billionaires

"The Commission strongly believes that growth strategies cannot succeed without a commitment to equality of opportunity, giving everyone a fair chance to enjoy the fruits of growth. But equal opportunities are no guarantee of equal outcomes. Indeed, in the early stages of growth, there is a natural tendency for income gaps to widen. Governments should seek to contain this inequality, the Commission believes, at the bottom and top ends of the income spectrum. Otherwise, the economy's progress may be jeopardized by divisive politics, protest, and even violent conflict. Again, if the ethical case does not persuade, the pragmatic one should."

According to this report global GDP went up from US\$ 5.31 trillion in 1950 to US\$ 77.6 trillion in 2014. Ironically, despite such a substantial increase in Gross Domestic Product of nations, incidence of poverty and malnutrition has gone up instead of coming down. Such vast disparity in income and wealth cannot be sustained for long. This will give rise to more and more criminal activities all over the world. This vast disparity could be reduced substantially if we could return to small and agro based industries instead of large MNCs. This will restore dignity of mankind; reduce unemployment and migration to cities, halt growth of urban slums and restore harmony between man and nature.

f) State of human health is yet another vital ingredient for sustainable development. Poverty and deprivation has always been a major cause for sickness and deaths. In the recent years increasing levels of consumption, massive urbanization and new comforts are also playing havoc with human health. These are popularly known as lifestyle diseases. In addition to contamination of air, water and soil; increasing stress levels due to rising greed, fast and unhealthy food, comfortable life style with no or very little physical activities, addiction to smoking, alcohol and drugs and excessive chemical intake in the form of pesticides, food preservatives and medicines are leading to increasing health problems across the globe. Despite rise in life expectancy, general health of people is much poorer than ever before. Despite increasing number of medical facilities, patients have to wait for weeks just to get an appointment. Precisely for this reason health industry has grown very fast during the last five decades. Pills have become a norm. According to the World Health Organization (WHO, 2012) the global public expenditure on health in 2010 was estimated to be US\$ 6.5 trillion, US spending being the highest at US\$ 8362 per person/year. According to the World Bank Indicators (World Bank, 2015) total expenditure on health care during 2013 was estimated at $9.9 \%$ of global GDP with $6.4 \%$ for low income countries and $11.9 \%$ for high income countries. In US the expenditure on health care went up from US\$ 356 in 1970 to US\$ 8364 in 2010 (KFF, 2015). Cardiovascular diseases are on rapid increase. Today $30 \%$ of total deaths are caused due to cardiovascular diseases and one in every 10 adult is suffering from diabetes (WHO, n.d.). New diseases like AIDs, heart ailments, Alzheimer, depression, obesity, chronic organ failure and a variety of cancers are becoming common affecting millions across the globe. Autism is becoming a serious problem. Sperm count is decreasing adversely affecting the reproductive capacity. These new and incurable diseases are posing a threat to human health and well-being, never seen before. All this is happening due to the developmental process we have embarked on since the industrial revolution.

\section{Conclusion}

The above processes are totally unsustainable. It is my firm conviction that the problem of sustainable development cannot be tackled simply by controlling the greenhouse or $\mathrm{CO}^{2}$ emissions. This is merely the tip of the iceberg. The global leaders will have to think in terms of reducing consumption levels so that the pressure on natural resources and consequent contamination of air, water bodies and soil is curtailed. Prudent are those who can manage with less. Excessive consumption is vulgarity. Austerity is wisdom. We must reduce consumption in the present if we want our progeny to survive. Excessive wealth is also the source and cause of large number of criminal activities, financial frauds, drug addiction, alcoholism, domestic violence and life-style diseases. Similarly large-scale production units must give way to small and rural production centres based on local raw materials to reduce glaring inequality of wealth and means of production, increasing unemployment, misuse of resources and massive contamination. This will also help in addressing the problem of unhealthy and artificial life-style, 
growing urbanization, urban slums, drugs trade and criminal gangs and in restoration of human face to economic activities.

After reading this article some people might wonder that I am asking them to go back in time. Yes I am, because our ancestors lived like that for thousands of years during pre-industrial period without playing havoc with nature and inviting nature's fury. They also gave birth to great civilizations in those times. If we do not do so we will be soon consigned to Stone Age by the very nature which is nurturing us. Mahatma Gandhi was far ahead of his time. In the first half of $20^{\text {th }}$ century he taught us the virtues of simple living, beauty of small and rural industries and the concept of trusteeship. The Middle Path of Gautam Buddha is far more relevant today than ever before. This is also the ancient wisdom enshrined in Vedas and many other scriptures around the world including the Bible which says that we do not live to eat but eat to live. Our ancestors were not unwise. It is time to heed them.

\section{References}

Baker, S., Kousis, M., Richardson, D., Young, S. (1997). Introduction: the theory and practice of sustainable development in EU perspective. In: The Politics of Sustainable Development: Theory, Policy and Practice within the European Union. (Baker, S., Kousis, M., Richardson, D., Young, S. (ed.)) pp. 1-40, Routledge, London and New York.

Brundtland, G. H. (1987). Report of the World Commission on Environment and Development: Our Common Future. [Online]. UN Documents. Available from: http://www.un-documents.net/our-common-future.pdf [Accessed: 3th March 2016]

Fey, W. R., Lam, A. C. W. (2001). The Bridge to Humanity's Future: A System Dynamics Perspective on the Environmental Crisis and its Resolution. [Online]. Ecocosm Dynamics Ltd. Available from: http://www. systemdynamics.org/conferences/2001/papers/Fey_1.pdf [Accessed: 6th March 2016]

Friends of the Earth (2009). OVERCONSUMPTION? Our use of the world' s natural resources. [Online] Friends of the Earth. Available from: https:// www.foe.co.uk/sites/default/files/downloads/overconsumption.pdf [Accessed: 7th March 2016]

GreenFacts (2013). Climate Change 2013, The Physical Science Basis. [Online]. GeenfFacts. Available from: http://www.greenfacts.org/en/climate-change-ar5-science-basis/index.htm [Accessed: 7th March 2016]

Gupta, G. S. (2014). Unraveling Mysteries of Life-Modern Science and Ancient Wisdom. $2^{\text {nd }}$ ed. Star Publications Pvt. Ltd., Delhi

Institute for Policy Studies (2016). Global Inequality. [Online]. Available from: http://inequality.org/global-inequality/ [Accessed: 6th March 2016]

IUCN (International Union for Conservation of Nature) (1980). World Conservation Strategy: Living Resource Conservation for Sustainable Development. [Online]. Available from: https://portals.iucn.org/library/efiles/ documents/WCS-004.pdf [Accessed: 3th March 2016]

KFF (2015). The Henry J Kaiser Family Foundation. Health Spending: Trends and Impact. [Online]. Available from: http://kff.org/health-costs/issuebrief/health-care-costs-a-primer/ [Accessed: 7th March 2016]
Krueger, R., David, G. (2007). Introduction: Problematizing the politics of sustainability. In: Krueger, R., David, G. (eds): The Sustainable Development Paradox: Urban political economy in US and Europe. pp. 1-11, Guilford Press, New York.

MGD (Millennium Development Goals) (2015). The Millennium Development Goals Report, 2015. [Online]. Available from: http:// www.un.org/millenniumgoals/2015_MDG_Report/pdf/MDG\%20 2015\%20rev\%20\%28July\%201\%29.pdf [Accessed: 6th March 2016]

NASA (2016). Global Climate Change, Vital Signs of the Planet. [Online]. Available from: http://climate.nasa.gov/evidence/ [Accessed: 6th March 2016]

National Geographic (2016). What is Global Warming? The Planet is Heating up and Fast. [Online]. Available from: http://environment.nationalgeographic.com/environment/global-warming/gw-overview [Accessed: 6th March 2016]

Shah, A. (2013). Global Issues, Poverty Facts and Stats. [Online]. Available from: www.globalissues.org. [Accessed: 7th March 2016]

UNFCCC (United Nations Framework Convention on Climate Change) (2015). COP 21/ CMP 11, Paris, 30 November to 12 December 2015. Paris Agreement. [Online]. Available from: http://unfccc.int/files/meetings/paris_nov_2015/application/pdf/paris_agreement_english_.pdf [Accessed: 6th March 2016]

UNGA (United Nations General Assembly) (2015). 70 $0^{\text {th }}$ Session 2015, A/ RES/70/1. Resolution adopted by the General Assembly on 25 September 2015, New York, United Nations. Transforming Our World: The 2030 Agenda for Sustainable Development. [Online]. Available from: http:// www.un.org/ga/search/view_doc.asp?symbol=A/RES/70/1\&Lang=E $>$ [Accessed: 6th March 2016]

UNFCCC (United Nations Framework Convention on Climate Change) (2014) .A Summary of Kyoto Protocol. [Online]. Available from: http://unfccc.int/ kyoto_protocol/background/items/2879.php [Accessed: 6th March 2016]

UNCSD (United Nations Conference on Sustainable Development) (2012). 7 Critical Issues at Rio+20. [Online]. Available from: http://uncsd2012. org/7issues.html [Accessed: 6th March 2016]

UNSD (United Nations Sustainable Development) (1992). Agenda 21. [Online]. Available from: https://sustainabledevelopment.un.org/content/documents/Agenda21.pdf [Accessed: 3th March 2016]

UN (United Nations) (2002). Gathering a body of global agreements. World Summit on Sustainable Development: Johannesburg Declaration on Sustainable development, 4 September 2002. [Online]. Available from: http://www.un-documents.net/jburgdec.htm [Accessed: 6th March 2016]

WHO (World Health Organization) (2012). Spending on Health: A Global Overview. [Online]. Available from: http://www.who.int/mediacentre/ factsheets/fs319/en/ [Accessed: 6th March 2016]

WHO (World Health Organization) (n.d.). 10 Facts on the State of Global Health. [Online]. WHO. Available from: http://www.who.int/features/ factfiles/global_burden/facts/en/index1.html [Accessed: 6th March 2016]

World Bank (2014). Commission on Growth and Development. The Growth Report, Strategies for Sustained growth and Inclusive Development, 2008. [Online]. Available from: http://siteresources.worldbank.org/ EXTPREMNET/Resources/489960-1338997241035/Growth_Commission_Final_Report.pdf [Accessed: 6th March 2016]

World Bank (2015). World Development Indicators: Health Systems. [Online]. Available from: http://wdi.worldbank.org/table/2.15 [Accessed: 7th March 2016] 